\title{
A materialidade dos acampamentos escolares e a cultura popular na 'Campanha de pé no chão também se aprende a ler'
}

\author{
The materiality of school camps and popular culture in \\ 'Campanha de pé no chão também se aprende a ler'
}

\author{
Fernanda Mayara Sales de Aquino \\ Universidade do Estado do Rio de Janeiro, Brasil, fernandamsaquino@gmail.com \\ Rosa Aparecida Pinheiro \\ Universidade Federal de São Carlos, Brasil, rosapinheiro115@gmail.com
}

\section{Resumo}

Ao refletirmos sobre a sobre a 'Campanha de Pé no Chão Também se Aprende a Ler', como marco das experiências de alfabetização e escolarização de crianças e adultos, identificamos a necessidade de entendermos a relação entre os acampamentos escolares e a cultura popular a partir da noção de cultura material escolar. As fontes utilizadas são o Relatório Cultura Popular e De pé no Chão (1963) e narrativas de professores que trabalharam na 'Campanha de Pé no Chão Também se Aprende a Ler'. A estrutura dos acampamentos escolares, com galpão circular onde aconteciam as festas com apresentações de grupos da cultura local, revela a centralidade que foi dada à cultura popular nos acampamentos e o tipo de relação que se buscava estabelecer entre o acampamento e a comunidade, uma relação de integração entre ambos os espaços.

Palavras-chave: Campanha de Pé no Chão Também de Aprende a Ler. Acampamentos escolares. Cultura material. Cultura popular.

\section{Abstract}

As we reflect on the ' Campanha de Pé no Chão Também de Aprende a Ler', as a landmark in the experiences of literacy and schooling of children and adults, we identified the need to understand the relationship between school camps and popular culture from the notion of school material culture. The sources used are the Popular Culture and Standing on the Floor Report (1963) and narratives from teachers who worked on the 'Campanha de Pé no Chão Também de Aprende a Ler'. The structure of the school camps, with a circular shed where the festivities took place with groups of local culture, reveals the centrality given to popular culture in the camps and the type of relationship sought to establish between the camp and the community, a relationship of integration between both spaces.

Keywords: Campanha de Pé no Chão Também de Aprende a Ler. School camps. Material culture. Popular culture. 


\section{Introdução}

O que passou não conta? Indagarão as bocas desprovidas.
Não deixam de valer nunca.
O que passou ensina
Com sua garra e seu mel.

Por isso é que agora vou assim No meu caminho. Publicamente andando. Não, não tenho caminho novo. O que tenho de novo É o jeito de caminhar.

(Thiago Mello)

A escolha pelos versos acima deve-se a nossa compreensão de que pesquisas com a história e a memória da Educação de Jovens e Adultos (EJA) e experiências de alfabetização destes sujeitos podem contribuir para as reflexões atuais referentes a essa modalidade de ensino. Do mesmo modo para destacar que, embora venhamos desenvolvendo pesquisas na área da história e memória da EJA desde 2010, ao optar por explorar a materialidade dos acampamentos escolares da 'Campanha de Pé no Chão Também se Aprende a Ler' recorremos ao campo da cultura material escolar (Hernández, 2002) e, portanto, "O que tenho de novo. É o jeito de caminhar".

Ao assumir a materialidade dos acampamentos escolares como objeto de investigação, no contexto da 'Campanha de Pé no Chão Também se Aprende a Ler', procuramos entender a concepção de educação e práticas educativas que fundamentavam a Campanha, os usos que foram feitos dos acampamentos escolares e a sua função política, social, pedagógica e cultural - questões que nos levam a compreender o seu caráter criativo em uma experiência de educação popular desenvolvida no contexto de efervescência política e cultural vivenciada pela capital do Rio Grande do Norte nos primeiros anos da década de 1960. Portanto, situar os acampamentos escolares em um espaço e tempo e interrogá-los nos trazem compreensões acerca das práticas pedagógicas da 'Campanha de Pé no Chão Também se Aprende a Ler' e de como a participação dos sujeitos envolvidos expandem as dimensões educativas do processo de socialização.

Las piedras y edifícios escolares hablan; también los pátios y lugares de encuentro del entorno escolar nos quieren decir algo, em el passado /y em el presente. Los objetos, los útiles y materiales del aula fueron y son instrumento de comunicación, ayer y hoy [...] Las cosas, los objetos, guardan um orden, cumplen una función en el aula [...] Es um orden convencional, impuesto, casual, visible a veces, o bien um sistema de relaciones invisible, ordenado, permitido, negociado o desestructurado em otras ocasiones. (Hernández, 2002, p. 225).

Fazendo uma analogia com Hernandez, as palhas e o chão de barro batido e a presença de objetos e espaços específicos, como aviários e hortas, falam da maneira como foram organizados os espaços de sociabilidades dos acampamentos e as práticas educativas possibilitadas em suas instalações. Assim, fundamentadas em Abreu (2005), escolhemos investigar os acampamentos escolares por compreender que o trabalho metodológico em cultura material escolar nos faz voltar 
o olhar para a busca de nossos mais corriqueiros objetos, "[...] pois é entre eles que se encontra aquele capaz de nos proporcionar uma verdade que nunca se precisou esconder, porque não havia outra para colocar em seu lugar e nem havia motivo para escondê-la." (Abreu, 2005, p.152).

Quando ponderamos sobre os acampamentos escolares e os interrogamos, queremos entender o caráter criativo dessas construções em um contexto de efervescência político e cultural, a concepção de educação e as práticas educativas, ou seja, o que os acampamentos nos informam sobre essas questões. Compreendemos o criativo com base nas formulações teóricas de Certeau sobre "as maneiras de fazer", pois para este autor, "maneiras de fazer' constituem as mil práticas pelas quais usuários se reapropriam do espaço organizado pelas técnicas da reprodução sociocultural" (Certeau, 2012, p. 41). Desta feita, definimos os seguintes questionamentos: como se deu a criação dos acampamentos escolares e o que isso nos revela? Neste contexto, qual era a concepção de educação da 'Campanha de Pé no Chão Também se Aprende a Ler'? Considerando que os acampamentos escolares foram pensados com as classes populares e para elas, como era a relação escola-comunidade?

A pesquisa com os acampamentos escolares e a busca por compreensões em torno dos questionamentos levantados ocorreu por meio da pesquisa documental, tomando como fonte o Relatório Cultura Popular e De pé no chão apresentado pela Prefeitura de Natal/Secretaria de Educação no 1ํ Encontro Nacional de Alfabetização e Cultura Popular (1963) e as narrativas de professores que trabalharam na 'Campanha de Pé no Chão Também se Aprende a Ler' - que são parte do acervo sobre a Campanha do Núcleo de História e Memória da Educação de Jovens e Adultos do Rio Grande do Norte (NUHMEJA-RN).

Com base nos achados da investigação, abordamos sobre o que foi a 'Campanha de Pé no Chão Também se Aprende a Ler', considerando o contexto político e cultural na qual foi criada, chamando a atenção para a criação dos acampamentos escolares e o que a sua materialidade nos revela sobre a Campanha. Neste contexto, abordamos as relações entre o acampamento escolar e a cultura popular em sua relação escola-comunidade como vetor de produção de conhecimento.

\section{A criação dos acampamentos escolares da "Campanha de pé no chão também se aprende a ler"}

Conforme assinalado, a 'Campanha de Pé no Chão Também se Aprende a Ler' foi uma experiência de alfabetização e escolarização de crianças e adultos desenvolvida em Natal, capital do Rio Grande do Norte, no período que compreendeu de 1961-1964. Contudo, para efeito de compreensão acerca da criação dos acampamentos escolares, convém discorrer sobre o contexto político e cultural da Campanha e a sua estrutura para posteriormente focarmos na compreensão sobre a criação dos acampamentos escolares e o que essa materialidade nos revela em relação à concepção de educação da Campanha e suas práticas educativas.

A "Campanha de Pé no Chão Também se Aprende a Ler" foi criada durante a gestão do prefeito Djalma Maranhão (1961-1964), que teve como secretário de educação Moacyr de Góes. Em Natal, sendo que o então prefeito era uma liderança 
que representava o pensamento das forças progressistas do Rio Grande do Norte. Segundo Góes (2010), a sua militância no cafeísmoi,

[...] assegurou a Djalma Maranhão a liderança de tendências que no Rio Grande do Norte, afinavam com o posicionamento de defesa do socialismo, da classe operária, do nacionalismo econômico, [...] do sindicalismo, da escola pública, do Estado laico, [...] da organização e mobilização das forças populares, da Revolução Cubana, do diálogo e aliança com todas as forças antifascistas e contra a corrupção. (Gòes, 2010, p. 34).

Natal, portanto, sofria as influências de um contexto nacional e internacional de grandes transformações políticas e sociais e Djalma Maranhão, como político de pensamento progressista e identificado com as causas populares, assumiu como meta número um diminuir o analfabetismo na cidade - onde a educação para todos e todas tornou-se pauta prioritária em sua administração. Em relação ao contexto cultural da Campanha, a identificação de Djalma Maranhão com as questões populares repercutiu na 'Campanha de Pé no Chão Também se Aprende a Ler', quando observamos em diálogo com professoras, que trabalharam na Campanha, a seguinte afirmação acerca do posicionamento de Djalma quanto às questões da cultura popular: "[...] ele fazia questão de que a cultura do Rio Grande do Norte, a cultura de Natal tivesse presente nos alunos da Campanha" (Marlene, 2011). É durante a gestão de Djalma Maranhão que foi desenvolvida uma política de democratização da cultura a partir da criação da Diretoria de Documentação e Cultura (DDC), que desenvolvia um trabalho de divulgação e revitalização do folclore e folguedos populares através de uma galeria de arte, museu de arte popular, bibliotecas populares, praças de cultura, apresentações teatrais.

Em relação à estrutura da 'Campanha de Pé no Chão Também se Aprende a Ler', embora este artigo tenha como foco de discussão dos acampamentos escolares, a sua estrutura não se resumia a eles, que a tornara nacionalmente e internacionalmente conhecida. Para além dos acampamentos escolares existiam escolinhas - que eram as classes de alfabetização que funcionavam em espaços cedidos pela população como casas, cinemas e igrejas. Destaca-se também o Centro de Formação de Professores, que teve a função de preparar e ofertar cursos de formação para os professores/as que iriam trabalhar na Campanha e realizar o trabalho de coordenação técnico pedagógica; uma Escola de Demonstração, que funcionava como escola de aplicação onde os/as professores/as em formação no Centro poderiam observar como acontecia a prática docente em sala de aula; os círculos de cultura, que consistiam em turmas de alfabetização de adultos tendo por fundamento teórico metodológico a abordagem freiriana; e a vertente De Pé no Chão Também se Aprende uma Profissão, em que foram oferecidos, nos próprios acampamentos escolares, cursos de barbearia, artesanato, enfermagem de urgência, encadernação, datilografia, corte e costura (Góes, 2010; Aquino, 2015).

Em relação aos acampamentos escolares destacamos a maneira criativa sobre como estes foram pensados e construídos, pois uma vez que o prefeito Djalma Maranhão havia sido eleito tendo como meta número um a erradicação do analfabetismo ele fora cobrado, pela população, para que fossem criadas mais escolas. Para dar uma satisfação a comunidade, o então Secretário de Educação Moacyr de Góes, em discussão com o Comitê Nacionalistaii das Rocas, explicara a impossibilidade de construção de novas escolas em razão da falta de recursos financeiros e buscava medidas, junto à população, que viabilizassem a erradicação do analfabetismo. Dessa discussão, adveio, por parte dos moradores presentes na 
reunião do Comitê Nacionalista das Rocas, a proposta de construção de acampamentos escolares cobertos com palha e feitos de chão de barro batido. (Góes, 2010). No Relatório Cultura Popular e De pé no chão apresentado pela Prefeitura de Natal no $1^{\circ}$ Encontro Nacional de Alfabetização e Cultura Popular no Recife, em 1963, consta a seguinte afirmação:

\begin{abstract}
Acampamentos Escolares: grandes galpões de 30x08 metros cobertos de palha de coqueiro e chão de barro batido. A construção é autenticamente obra de Cultura Popular, usada pelos pescadores das praias nordestinas, herdeira em linha reta da habitação indígena. Uma curiosidade: os operários da Prefeitura não souberam construir o primeiro acampamento. Foram chamados os pescadores do 'Canto do Mangue', praia das proximidades, conhecedores da técnica da 'virada' e da 'armação da palha'. (Natal, 1963, p. 7).
\end{abstract}

Portanto, em razão da falta de recursos da prefeitura para construir escolas, moradores do bairro das Rocas criaram uma alternativa aos clássicos prédios escolares com a proposição dos acampamentos escolares. Para construção destes foram usados os materiais e habilidades próprias da sua cultura praieira a fim de que Ihe fosse garantido o direito à educação. Nesse sentido, é que consideramos o caráter criativo dos acampamentos escolares como uma arte ou "maneiras de fazer" (Certeau, 2012) em uma experiência de educação popular desenvolvida em um contexto de efervescência político e cultural. "[...] A 'cultura popular' se apresenta diferentemente, assim como toda uma literatura chamada 'popular': ela se formula essencialmente em 'artes de fazer' isto ou aquilo, isto é, em consumos combinatórios e utilitários" (Certeau, 2012, p. 41). A população pensou, propôs e ajudou na construção de outros modos e lógicas de prédio escolar, "as escolas de palha", das quais, sobre a construção e estrutura dos acampamentos escolares, José Ribamar, funcionário da prefeitura, e Marlene Araújo, professora da 'Campanha de Pé no Chão Também se Aprende a Ler', afirmam:

Os galpões eram construídos da seguinte maneira: nós aplanava o terreno. Naquele tempo não existia máquina, mas eu mandava tirar argila de um terrenozinho especial e o caminhão trazia a argila e a gente espalhava a argila no ambiente do galpão. Se aguava aquela argila e se batia com malha de ferro. A argila encorpa, fica dura [...] a gente costumava muito mandar aguar todo dia de manhã antes de começar a aula, para não ter poeira para as crianças [...] tinha sempre um ginásio, um daqueles grandes redondos [...] tudo tudo era lá, folclore, apresentado no ginásio. Agora as cozinhas eram no fundo do galpão e eram de alvenaria [...] as crianças lanchavam no galpão. Tinha uma horta e um chiqueiro. (José, 2011).

Fisicamente eram paupérrimos; madeira de pau a pique, cobertura de palha. Agora uma cobertura muito bem feita, não tinha parede. A separação era por tabiques, barro batido. Era assim os acampamentos. A água era umas gamelas grande, uma vasilha com água, a iluminação muito ruim. Porque nessa época nós não tínhamos Cosern e nem coisíssima nenhuma. Então a estrutura física era muito, muito frágil. (Marlene, 2011).

As narrativas acima trazem traços acerca da materialidade dos acampamentos escolares (o barro batido, a palha, a madeira de pau a pique, a horta, o chiqueiro, as cozinhas de alvenaria, o espaço para os festejos populares), sendo preciso atentar, portanto, para função dessa materialidade no contexto dos acampamentos escolares. Qual a finalidade dessa estrutura e o que era possível realizar por meio dela em termos de educação? Segundo Aquino (2015), os acampamentos escolares foram compostos por um galpão circular, onde aconteciam 
as festividades do bairro com apresentações de grupos de cultura popular e as reuniões de pais e professores; e por galpões em forma retangular, onde funcionavam as salas de aulas e uma pequena sala de alvenaria que servia como diretoria, secretaria e almoxarifado. Nas dependências destes acampamentos escolares também existiam aviários e hortas, que permitiam a produção da merenda escolar para as turmas de crianças, que funcionavam durante o dia. No período noturno eram oferecidas aulas de alfabetização para os adultos, que em geral eram pais das crianças que estudavam no mesmo acampamento pela manhã ou à tarde. Em 11 de fevereiro de 1963 passaram a ser ofertados, nos acampamentos, cursos da vertente de Pé no Chão Também se Aprende uma Profissão.

Segundo Hernandez (2002, p. 232), os objetos e prédios escolares além de apresentarem uma materialidade e uma função nos dizem coisas acerca dos usuários, da sociedade, dos métodos de ensino empregados. "Los objetos hablan, si se les deja". Nesse sentido, o que os acampamentos escolares nos revelam sobre a Campanha? Considerando a maneira como foram criados e a disposição de sua materialidade e funções, os acampamentos escolares nos informam, sobretudo, acerca da concepção de educação da 'Campanha de Pé no Chão Também se Aprende a Ler', bem como acerca de suas práticas educativas.

A criação dos acampamentos escolares como uma ideia que parte da população do bairro das Rocas em razão das suas necessidades por mais escolas, sendo o primeiro acampamento criado neste bairro e o envolvimento dos moradores no processo de construção do primeiro acampamento escolar, revela traços de uma educação popular. Educação popular entendida na perspectiva de Melo Neto (2002) que, entre outras dimensões, afirma que para algo ser considerado popular, precisa ter origem nos esforços e trabalhos do povo; se faz necessário que a direção ou as medidas tomadas beneficiem as maiorias (povo); ter uma dimensão política voltada à defesa dos interesses das maiorias que estão às margens do fazer político dominante; por fim, ser popular envolve a sustentação de utopias, que abrem a possibilidade para tentativa de novas realizações. Portanto, ainda sobre a criação dos acampamentos escolares, a profa. Margarida Cortez afirma:

Numa das reuniões dos comitês alguém sugeriu que se fizessem escolas de palha de coqueiro [...]. Eram muito rústicos, o chão era barro batido e as classes eram divididas por algumas tábuas de tal forma que as vozes das professoras não interrompessem o andamento dos trabalhos. (Margarida, 2012).

A narrativa da professora Margarida nos remete aos estudos de Certeau, pois há por parte da população, representada por aqueles que faziam parte do Comitê Nacionalista, uma espécie de resistência à realidade que lhes foi apresentada; uma alternativa criativa dos sujeitos para enfrentar a falta de recursos para construção de prédios escolares. Essa astúcia dos integrantes do Comitê Nacionalista nos envia ao conceito de trampolinagem (Certeau, 2012) - palavra associada à astúcia de os indivíduos utilizarem ou driblarem os termos dos contratos sociais, a fim de criar outros movimentos, outros resultados. Nesse sentido, compreendemos experiências de educação popular como espaço fértil de criações e invenções, por parte dos sujeitos, que auxiliam a superar realidades sociais, que muitas vezes, o oprimem ou lhe negam direitos; nesse caso, direito à educação (Aquino, 2015).

O acampamento escolar, considerando toda a sua estrutura explicitada anteriormente, era espaço de acesso ao direito à alfabetização, escolarização e 
aprendizagem de um ofício com a implantação da vertente de 'Pé no Chão Também se Aprende uma Profissão' em 1963. Além disso, a presença de aviários e hortas, cozinha, de uma sala que funcionava como diretoria e almoxarifado, e o galpão circular onde aconteciam as reuniões de pais e festas populares faziam do acampamento um espaço cuja prática educativa considerava o indivíduo em sua complexidade social, cultural, biológica. Ou seja, os alunos e alunas,

[...] como sendo parte de uma realidade simultaneamente biológica, psíquica, social e cultural. Buscam-se as possibilidades e espaços diferenciados para mudança não só do sistema educativo, mas também do social, e que englobe o reconhecimento da singularidade dos sujeitos em uma unidade do copo social. (Pinheiro, 2011, p. 96).

\section{Os acampamentos escolares e a cultura popular}

Ao pensarmos sobre as relações entre o acampamento escolar e a cultura popular, passando pela relação escola-comunidade, identificamos na existência de um galpão circular, destinado às reuniões de pais e professores/as, aulas de recreação e-festividades do bairro com apresentações de grupos de cultura popular, a importância destinada a cultura local e a preocupação em se estabelecer relações entre a escola e a comunidade. Nesse sentido, destaco as falas das professoras Maldi Linhares e Salonilde Ferreira:

\footnotetext{
O acampamento era um centro de cultura. Tudo da comunidade acontecia ali. As festas, o resgate das festas tradicionais - pastoril, fandango - [...] acontecia as festas nos acampamentos. (Salonilde, 2011).
}

Passou um tempo aí eu fui para palhoça de Chico Santeiro. [...] Eu fui ser vice-diretora dessa palhoça. Tinha muitos alunos, muitas salas de aulas [...] (Maldi, 2011).

As falas destas professoras revelam a centralidade que era dada à cultura popular nos acampamentos escolares e o tipo de relação que se buscava estabelecer entre o acampamento e a comunidade em uma relação de integração entre ambos os espaços. Destacamos, ainda, o nome de Chico Santeiro (um artista popular da época que fazia esculturas de madeira) dado a um dos acampamentos, e, nesse sentido, afirmamos que se buscava, em meio à organização das práticas educativas da Campanha, o respeito à diversidade e a valorização das especificidades culturais da comunidade. Segundo Góes (2010, p. 91) "Era política expressa da Secretaria Municipal de Educação vincular o Acampamento às organizações populares e lideranças culturais mais expressivas do bairro onde se localizava."

A "Campanha de Pé no Chão Também se Aprende a Ler", por se tratar de uma experiência de educação popular, tem a valorização da cultura popular como um dos seus fundamentos - que se expressa no Relatório Cultura Popular e De pé no Chão apresentado pela Prefeitura de Natal no 1ํㅡㄹ Encontro Nacional de Alfabetização e Cultura Popular no Recife, em 1963, com esta temática como eixo central, conforme o título já sugere. Há uma discussão conceitual sobre cultura popular, que deixa claro a preocupação em fazer com que a educação ofertada na 'Campanha de Pé no Chão Também se Aprende Ler' pudesse contribuir para integrar alunos e alunas a sua comunidade. 
O significado do termo cultura popular assume para nós forma definida a partir da compreensão mais profunda da situação de dominação externa a que está submetido o Brasil, desde o seu descobrimento, até os dias atuais. [...] A nossa luta interna de libertação liga-se profundamente à cultura popular, que assume no primeiro momento o sentido de desalienação de nossa cultura, sobrepondo-se aos valores culturais estranhos aos nossos valores que são criados e elaborados aqui. [...] Num segundo momento, assume a cultura popular um caráter de luta, para que, ao lado da formação de uma autêntica cultura nacional, promova a integração do homem brasileiro no processo de libertação econômico-social e político-cultural do nosso povo. Cultura popular que leve o homem a assumir o papel de sujeito da própria criação cultural, fazendo-o não apenas receptor, mas, principalmente, criador de expressões culturais [...]

A alfabetização, constituindo um núcleo de toda uma obra de cultura popular, deve ter como objetivo máximo integrar o educando na sua comunidade, dando-lhe para isto a oportunidade de sentir e viver a cultura de seu povo. (Natal, 1963, p. 1, 4).

A exemplo dessa busca de coesão entre a educação ofertada pela 'Campanha de Pé no Chão Também se Aprende a Ler' e a cultura popular, destacamos também a inclusão no cotidiano dos acampamentos escolares de apresentações de grupos da cultura local. Segundo Góes,

[...] pouco a pouco, surgiam iniciativas comuns entre o Acampamento das Rocas e a Sociedade Araruna de Danças Antigas; entre o Acampamento de Aparecida e o fazedor de imagens Chico Santeiro; entre o Acampamento de Conceição e o Bambelô Asa Branca; entre o Acampamento do Carrasco e os Congos e/ou Boi-Calemba. (Góes, 2010, p. 91).

Compreendemos que a integração da cultura popular nas escolas é importante por ser o meio que associa diversão e a cultura dos alunos no ambiente escolar, valorizando suas concepções culturais e sociais e ajudando a fortalecer as experiências dos aprendizes. Segundo Giroux e Simon (2000, p. 96) "A cultura popular é organizada em torno do prazer e da diversão, [...] é apropriada pelos alunos e ajuda a validar suas vozes e experiências." As ações em termos de integração da cultura popular na 'Campanha de Pé no Chão Também se Aprende a Ler', posteriormente, não se restringiram aos festejos populares realizados nos acampamentos, mas se desdobraram na criação de praças de cultura, do Teatrinho do Povo, Galeria de Arte, círculos de leitura, Museu de Arte Popular, reativação de grupos de danças folclóricas (Germano 2010, Aquino, 2015).

\section{Considerações Finais}

Nas discussões que foram desenvolvidas, neste artigo, em torno da materialidade dos acampamentos escolares da 'Campanha de Pé no Chão Também se Aprende a Ler', procuramos compreende-la a partir das contribuições do campo da cultura material escolar. Buscamos discutir o caráter criativo dos acampamentos escolares em uma experiência de educação popular desenvolvida em um contexto de efervescência política e cultural.

Destacamos o caráter criativo dos acampamentos escolares como uma arte ou "maneiras de fazer" (Certeau, 2012), pois a população pensou, propôs e ajudou na construção de outros modelos de prédio escolar, "as escolas de palha". A criação dos acampamentos escolares como uma ideia que parte da população e a 
participação de pescadores no processo de construção do primeiro acampamento revelam dimensões práticas de uma experiência de educação popular. Além disso, a estrutura dos acampamentos escolares, com galpão circular onde aconteciam as festas com apresentações de grupos da cultura local, revela a centralidade que era dada à cultura popular nos acampamentos e o tipo de relação que se buscava estabelecer entre o acampamento e a comunidade, uma relação de integração entre ambos os espaços.

O trabalho com a história e a memória dos acampamentos escolares da "Campanha de Pé no Chão Também se Aprende a Ler" nos permite olhar para o passado e perceber como se dava a valorização da cultura popular no contexto das práticas educativas da Campanha. A nosso olhar, destaca-se o envolvimento dos sujeitos a partir de suas vivências ou das materialidades de suas experiências que se transformam em potenciais educativos.

Embora a experiência analisada tenha um tempo histórico datado, suas fundamentações e escolhas sócio educativas transpassam a época vivenciada e podem ser transpostas para tempos atuais. A importância do trabalho com a materialidade dos acampamentos escolares dá visibilidade aos sujeitos como produtores em seus atos cotidianos e em suas potencialidades na ressignificação do ato educativo imbricado as existências materiais possíveis. Retomar estas práticas educativas ressalta o que podemos visualizar como possibilidades educacionais em práticas escolares e não escolares, no sentido de contribuir para as reflexões atuais referente aos campos da Educação Popular e da Educação de Jovens e Adultos.

\section{Referências}

Abreu, L., M., Jr. (2005). Apontamentos para uma metodologia em cultura material escolar. Pro-Posições, v. 16, n. I (46), p. 145-164.

Aquino, F., M., S. (2015). O cotidiano da formação de professores/as da 'Campanha de Pé no Chão Também se Aprende a Ler'. Dissertação de Mestrado, Universidade Federal do Rio Grande do Norte, Natal, Rio Grande do Norte, Brasil.

Certeau, M. (2012). A invenção do cotidiano: 1. Artes de fazer. (19a ed.). Petrópolis: Vozes.

Germano, J., W. (2010). Lendo e aprendendo: a campanha de pé no chão. (3a ed.) Natal: Palumbo, 2010.

Giroux, H., A.; \& Simon, R. (2000). Cultura popular e pedagogia crítica: a vida cotidiana como base para o conhecimento curricular. In: Moreira, A. F.; \& Silva, T., T. Currículo, cultura e sociedade. (4a ed.) São Paulo: Cortez.

Góes, M. (2010). De Pé no Chão Também se Aprende a Ler: (1961-1964) uma escola democrática. (3a ed.). Natal: Palumbo.

Hernández, D., J., M. (2002). Etnografia e história material de la escuela. In: Escolano B., A. La memoria y el deseo: cultura de la escuela y educación deseada. Valencia: Tirant lo Blanch.

José, R. José Ribamar: depoimento [set. 2011]. Entrevistadora: Fernanda Aquino e Marisa Sampaio. Natal: NUHNEJA-RN, 2011. $110 \mathrm{~min}$. WAV. Entrevista concedida ao Núcleo de História e Memória da Educação de Jovens e Adultos - RN. 
Maldi, L. Maldi Linhares: depoimento [ago. 2011]. Entrevistador: Yuri Bortoni. Natal: NUHNEJA-RN, 2011. 45 min. WAV. Entrevista concedida ao Núcleo de História e Memória da Educação de Jovens e Adultos - RN

Margarida, C. Margarida Cortez: depoimento [maio. 2012]. Entrevistadora: Marisa Sampaio. Natal: NUHNEJA-RN, 2012. $91 \mathrm{~min}$. WAV. Entrevista concedida ao Núcleo de História e Memória da Educação de Jovens e Adultos - RN.

Marlene, A. Marlene Araújo: depoimento [ago. 2011]. Entrevistadores: Fernanda Mayara. Natal: Residência da entrevistada, 2011. 80 min. WAV.

Melo, J., F., N. O que é popular? Recuperado em 28 de setembro, 2017, http://www.prac.ufpb.br/copac/extelar/producao_academica/artigos/pa_a_2002_o_qu e_e_popular.pdf

Natal (1963). Secretaria de Educação, Cultura e Saúde. Relatório cultura popular e pé no chão. In: Fávero, O.; \& Motta, E. Educação Popular e Educação de Jovens e Adultos. (2015). Petrópolis, RJ: De Petrus et Alli; Rio de Janeiro, RJ: FAPERJ.

Pinheiro, R., A. (2011). Saberes na proposição curricular: formação de educadores de jovens e adultos. Natal, RN: EDUFRN.

Ferreira, S. Salonilde Ferreira: depoimento [set. 2011]. Entrevistadores: Francisco Alves, Marisa Sampaio, Rosa Aparecida. Natal: NUHMEJA-RN, 2011. 48 min. WAV. Entrevista concedida ao Núcleo de História e Memória da Educação de Jovens e Adultos - RN.

\section{Notas:}

\footnotetext{
' Grupo que reunia as forças progressistas do Rio Grande do Norte, sob a bandeira de luta contra o Estado Novo e o fascismo.

ii Comitês Nacionalistas, instalados em muitos bairros da cidade do Natal, são os locais onde ocorriam discussões em torno de problemas sociais. (Germano, 2010).
} 